\title{
Cinematography and Storytelling
}

\author{
Cedric van Eenoo
}

\begin{abstract}
In this study, pictures and their properties are examined as instruments of storytelling. Cinematography is generally utilized to generate style and to give the film a characteristic appeal. But in some instances, images actually influence the narrative itself in ways that can re-orientate the plot, and at times, entirely modify it. The essence of the story can emerge from observation and introspection, as opposed to a plot built in a cause-andeffect arrangement. In this study, images and their properties are examined as potentially the sole instrument of storytelling. The analysis focuses on the sensuous characteristics of on-screen pictures that can be considered alternative footage, connecting shots, or intercuts and how they generate meaning. In this perspective, the story emerges as implicit, with a non-representational approach to filmmaking, in the manner poems utilize metaphors. However, this does not necessarily imply the absence of narrative. In this regard, the concept of time-imageimage infused with time - is fundamental: a picture embeds connections to other time and space modules. If the story and the images of the film are intricately intertwined, in a relation of sounds, visuals and emotions, the balance between the two roles can be manipulated, resulting in a different approach to filmmaking. In this configuration, the similarly secondary elements of the story become the main narrative mechanism, through the simultaneous experience of viewing, feeling and interpreting.
\end{abstract}

Keywords: Film, Cinema, Image, Cinematography, Narrative, Storytelling

DOI: $10.7176 /$ RHSS/11-20-03

Publication date:October $31^{\text {st }} 2021$

\section{Introduction}

Cinematography is by definition 'the art or technique of motion-picture photography' (Dictionary, 2021). The understanding of cinematography starts with the properties of pictures, as it does with visual arts more broadly. However, in this case the pictures are part of a succession of images, so the connection to photography and painting is significant: it suggests that storytelling can find a justification in the visual attributes of the film, through a development in time.

Cinematography is typically utilized to give the film a certain appeal and visual style. But in some instances, it actually influences the narrative itself in ways that can re-orientate the story and, at times, modify the understanding of the plot. To further elaborate on this concept, images have the potential to become the fundamental instrument of storytelling. In this case, the film relies on the visual characterization of pictures, the generation of atmosphere, and the intrinsic properties of images, with a non-representational approach to filmmaking, in a similar manner poems employ metaphors. However, this does not necessarily imply the absence of a story. Two perspectives are distinct and often at odds in this approach: video art and art installations, with the choice to distance the work from narrative mechanisms, and motion pictures that can be watched sitting in a theater, where the audience expects a story to be told without too much interference of abstract images. Experimental films can attempt to reconcile these two distinct formulas and use methodologies that belong to both practices. The focus can remain on storytelling, but produce innovative propositions that experiment with narrative techniques that are primarily based on visuals.

\section{Image Properties}

When the mechanisms of the film are based on atmosphere, the role of cinematography becomes more important, because it represents the primary mode of interaction with the viewer. In this sense, there is a clear analogy with art installations and music videos. Specific technical aspects, such as image tint, grain, texture, but also sound, convey the message. In a similar manner, with visual communication, the understanding of a film can be immediate and intuitive, based on visual impressions and the psychological or physical implications that they carry (Goldstein, 1942, p. 147). This phenomenon of visual impression actually occurs 'without conscious awareness or intention' (Elliot \& Maier, 2007, p. 250). The notion is important, because during a movie, the audience does not need to process this information. It is in fact naturally communicated through visual mechanisms outside of the plot to address the emotional states and feelings evoked in the story.

In this regard, cinematic storytelling can actually be apprehended on different levels: when the visual components are reduced, time and space are enlarged, offering a wider interface for the audience to relate with the movie, but on a level of sensations. This happens when the film can operate in connection with the themes of the story, as it is perceived, and not with the plot and its structural mechanisms. The movie then operates through imagery, without the use of conversations, action, or cause-and-effect. This method encourages a personal involvement with the film and, subsequently self-reflection, in analogy with abstract painting. 
In Happy Together, Hong Kong director Wong Kar-Wai presents sophisticated elements of color composition to elaborate moods that genuinely take the lead in the narrative method of the film, communicating emotions before telling a story (Wong, 1997). In this instance, clearly, 'cinematography creates meaning' (Greenhalgh, 2005, p. 195). The tints convey the message, without relying solely on plot development.

Similarly, with Playtime, Jacques Tati utilizes tints to represent the development of the story into a different stage (Tati, 1967). Hues are used for their immediate effect on the perception of the story: cold colors and dark shades of gray accompany the rigid structures of lines in modern glass buildings in the first part of the movie, accompanying stress and despair in the middle of an impersonal world. They are opposed to warm colors and colorful images in the second half of the story, where the experience becomes more enjoyable and positive. This notion emphasizes the fundamental role that color can play in the perception of the story (Verstraten, 2009, $\mathrm{p}$. $65)$.

Likewise, John Ford's western The Searchers displays intense color values throughout the movie (Ford, 1956). The pictures exhibit magnificent natural backgrounds in the old American west: sunsets, snowfall, dusk and dawn light, used in different contexts, intensify the tone of the scenes and give the film its personality. Sophisticated images exhibit highly saturated and rich colors; vibrant warm images emphasize the concentration on the natural environment and the characters, which transpires to be a typical trait of the director. This technique stands as a parallel narrative to the action; it generates a sense of beauty in an otherwise harsh and cruel story.

In addition, depth of field, perspective and focal length are technical instruments of storytelling that allow the operation of the work on a purely visual level, with no relation to time or structure. Manipulated contrast, color correction, hue saturation can become mechanisms of narrative delivery, in parallel to the plot.

Another illustration of efficient manipulation of grayscale shades is The Turin Horse by Hungarian directors Ágnes Hranitzky and Béla Tarr, who uses black and white to emphasize the harsh and austere atmosphere of the story (Hranitzky \& Béla Tarr, 2011). Depicting harsh living conditions and a hostile climate, the filmmaker uses intense cold monochrome and raw texture to communicate his radical view, based on an episode of Friedrich Nietzsche's life (Koehler, 2011). The movie was inspired by the painting The Potato Eaters, by Vincent van Gogh (1885). The narrative itself is virtually contained in the cinematography. The director mentions his opinion on stories, stating that they are all similar; he claims that 'the film isn't the story', but is 'mostly picture, sound, a lot of emotion' (Kohn, 2012, para. 9).

\section{Framing}

Framing plays an essential role, because it will offer an orientation to apprehend the time and movement that the image contains. For instance, closeups are used in more intimate situations. To some extent, they can be the 'coordinates of the narrative' (Doane, 2003, p. 107). Conversely, wide angles are generally instruments of action in films, to emphasize movement and speed (Greenhalgh, 2005, p. 207). In a movie that is concerned with sensations, emotions, or self-reflection, a closeup shot serves the interest of the scene's intensity, as it can become, to cite film theorists Jean Epstein and Stuart Liebman, the 'soul of cinema' (Epstein and Liebman, 1977, p. 9).

The framing of the subjects in film is a decision made in the same approach as the storytelling method. Positioning certain elements of the scene outside of the picture is an analogy of the omission of components of the plot in the narrative method. It generates a style that converges with the 'aesthetic of absence' (Degli-Esposti 1998, p. 38). The purpose is to relocate what is not present before the eyes: the essence of human thoughts and feelings. The visible objects or actions are given a secondary role. Besides, the aesthetic of absence 'embraces time' (Sayre 1983, p. 174). Its nature is to allow the viewer to connect the past-and future - of the subject with the space and context, to let meaning emerge; and by this process, to be involved in an external dimension of the storytelling. This is in direct association with the concept of time-image and the intensity it can generate in a cinematic story (Deleuze 1989, p. 42).

\section{Grain, Noise, Imperfection}

Further to aesthetic considerations, cinematography can be granted new roles when every image of a movie is considered an artwork. Grainy pictures, for example, can communicate a sense of realism (Lam, 2013). In addition, the use of noise in the images renders a unique quality of roughness and intimacy, which is often employed in independent cinema. It can also be a way of reconnecting to more simple ways of filmmaking. For instance, Bicycle Thieves possesses a unique aesthetic of unsophisticated honesty for their image quality (De Sica, 1948). Imperfect pictures can generate a sense of emotional proximity with the audience.

In this regard, image quality can be related to the Japanese art of Wabi-Sabi and the sense of elegance found in irregularity or defects. In this perspective on art, flaws are praised for the refinement they imply, reflecting 'simplicity, purity, and humility' (Juniper, 2011, p. 62). With imperfections, the art becomes precious and can be the medium of 'ingenuous integrity' (Rognoli \& Karana, 2014, p. 148). This notion can be directly applied to the 
properties of film images. The overall aesthetic of the work appears more intimate with 'film's grain and its limited tonal range' (Manovich, 2005, p. 30). It compresses the scope of hues on screen, which tends to converge the attention of the audience and gives a quiet character to the pictures. It also changes the spirit of the scenes, giving the story a more down-to-earth nature. It is even more pertinent when the substance of the film is sensuous or emotional. Image noise can 'enhance contrast and intensify grain' (Prince, 2004, p. 27). Besides, it enables harmony in the different segments of the film, when there are dissimilarities in light, tints and sharpness, creating a feeling of unity, but at the same time keeping the variety of tones in each sequence in accordance with the tone of the specific segment. A sense of authenticity can be brought to the work. As a matter of fact, this type of visual manipulation mirrors the practice of painting, with the work on color mixing and impasto to create texture on the surface of the canvas. It offers limitless possibilities to tell a story, with manipulation in postproduction. In this regard, it 'opens up avenues for visual and narrative innovations' (Geuens, 2002, p. 16). Conceptually, it is not an artificial process: the act of filming and editing a movie is a simulation itself (Manovich, 1996). This practice is a part of the grammar used to achieve a goal of communicating a message. Paradoxically, the artistic alteration of pictures in their visual properties appears more truthful to the real world. For instance, with the movie Life in a Fishbowl, Icelandic film director Baldvin Zophoníasson uses image texture - accentuated by low light - and noise to emphasize the intimate approach to the story of the different characters' personal lives, especially the female protagonist Eik, played by Hera Hilmar, and her inner conflict (Zophoníasson, 2014). This technique renders the story more poignant and the scenes more touching because the overall tone of the work appears close to a documentary film in its perceived authenticity. With a grainy image, film offers a more familiar, naturalistic view. In this process, film grain and image noise work to transcend the banality of the subjects. It appears realistic, brings the audience closer to the story, and simultaneously transposes the focus further from the ordinary, giving it a new point of view, so that the audience can interpret what is seen in an individual perspective. The mechanism at play here is not imagination, but sensation. As opposed to text, with film, visuals have the ability to address the senses directly. The cognitive process is relegated to the role of recomposing the story with the missing scenes.

\section{Emotional Dimension}

Emotion is considered an essential element of the cinematic experience. According to scholar Ian David, narratives themselves rely on emotions (David, 2014, p. 49). The story, being a link between the viewer and the author, Ian David affirms that narratives are modeled on the underlying emotional variations. Based on this notion, a story can develop according to purely sensation-based structures, which operate naturally, in relation to the audience's unique emotional reaction to the work, not necessarily in response to an architecture of causality and logical development.

When the spectator engages emotionally with the movie, the assimilation of new knowledge from the experience can happen (Graham, Ackermann \& Maxwell, 2004, p. 54). It can be through identifying with the characters, experiencing the emotions in the scenes, reflecting on this identification, or trying to apply the concepts learned from the story in personal situations (Graham et al 2004, p. 49). This method is, in fact, very useful in the narrative itself because it orchestrates the understanding of the viewer through feelings. It becomes the entry point to the plot and the guide to the development of the story: emotion becomes a vehicle for the narrative. Considering this role, it can be treated according to the impact it will have on the film, in respect to the importance it has in the story, and in parallel to the understanding of the plot.

In fact, if the narrative operates efficiently, the response of the viewer is authentic; it means that the feeling in the story is treated as an actual feeling in life. Thomas Wartenberg, with his studies of the impact of imagination on film audiences, describes the emotional effect of a virtual situation, in this instance a scene from a movie, and declares that it is similar to a real-life situation, without the reaction (Wartenberg, 2008). It can actually generate a physical reaction similar to the actual situation, crying when watching a touching scene in a movie verifies this statement.

In addition, with Film Narratology, Peter Verstraten focuses on film narratives and especially what makes it distinct from other disciplines, with cinematography, mise-en-scene, editing, visual narrative and sound (Verstraten, 2009, p. 49). By looking at the elements that clearly differentiate themselves from literature and basic structure in time, the study can discern the unique characteristics of storytelling in cinema. Peter Verstraten questions the role of narratology in films and claims that not every viewer actually sees the same story (Verstraten, 2009, p. 29). The perception depends on the various backgrounds, types of sensitivity and receptivity of the audience. But to be able to read the different strata of the film, the director must operate at different levels and, in doing so, utilize more than a composition of scenes, but also the visual impact of images. This demonstrates the importance of the visual elements in the understanding of the story.

However, Peter Verstraten makes clear that relying too much on filming effects can weaken the story. Nevertheless, he adds that in some cases, extreme style can be the method to convey the message (Verstraten, 2009 , p. 203). It is always a matter of measure, but the real question is first and foremost how style serves the 
message behind the work. Concept can be the starting point and guideline of creation, as it is, for instance, in fine art.

For example, the movie Brazilian City of God, co-directed by Kátia Lund and Fernando Meirelles tells the story of a group of teenagers involved in organized crime in the underprivileged suburbs of Cidade De Deus in Rio de Janeiro (Lund \& Meirelles, 2002). Vivid, warm colors, film grain, rich textures, unstable camera shots and the use of real-life residents of the area, as actors, support the realistic style of the work. The saturated images reflect the violence of the story. It creates a one-of-a-kind experience, where the viewer is immersed in the story world, so that the plot itself can appear secondary. In this perspective, pictures transform into narrative mechanisms, and in essence, cinematography becomes storytelling.

With Carl Plantinga's examination of mainstream movies, the emotional dimension of films is further explored, especially its role in cultural, philosophical and aesthetic contexts (Plantinga, 2009). References to philosophy, psychology and cognitive science support the author's study of the experience of emotions in cinema, through distinct mechanisms. Carl Plantinga states that the viewer's 'emotions are typically elicited by external stimuli provided by the film, but responses to such stimuli are dependent on the memories and associations the viewer brings to the film' (Plantinga, 2009, p. 75). The fact that the emotional relation with the movie operates on a personal level of experience shows that the audience does connect to the story through sensations, hence, does understand the plot according to this very experience. So, even if it carries a different significance, the emotional charge is present and serves the learning process throughout the film. It is a channel for the intensity of the story to be communicated. But while emotion is often a result, it is seldom a means. Emotion could in fact not only support, but also drive the narrative, in efficient ways, if it is the main perspective of the work. This is true, even if only a scene is extracted from the entire movie; the viewer can be involved in an isolated sequence to find meaning and reflect on its implications on real life, based on individual reflection.

With its diverse mechanisms, Carl Plantinga demonstrates that the cinematic experience is extremely variable (Plantinga, 2009, p. 77). The fact that it remains at a personal level of experience proves that the viewer does connect to the story through sensations, hence, does understand the plot according to this very experience. So, even if it carries a different significance, the emotional charge is present and serves the learning process throughout the film. It is a channel for the intensity of the story. While emotion is often a result, it is seldom a means. Emotion could actually support - even drive - the narrative in extremely efficient ways.

For instance, with Take Shelter, director Jeff Nichols depicts a series of nightmares in scenes that appear incredibly realistic, and mesmerizing at the same time. The spectator is immersed in the sensations of the dreamer (Nichols, 2011). Without referring to the plot at any time, or having to relate to the story as a whole, the standalone sequences lead the emotional experience-guiding the overall narrative, in the absence of causal connections to the story development. This notion of sensorial experience in film is closely tied to the in-depth role of cinematography and its relation to the narrative method, as it identifies the emotional interaction with the work as an instrument of storytelling.

Additionally, a look at design and visual communication can help better discern the role of pictures in films. Images are compared to textual explanation and information: pictures carry an immediate appeal and intuitive meaning that operates efficiently at different levels (Lankow, Ritchie \& Crooks, 2012, p. 40). As an extension, the characteristics of images in movies are undeniably significant: they carry more meaning than actions, conversations or events. The role of cinematography can, in some cases, replace the need to tell with the possibility to show. For instance, in Manchester by the Sea, director Kenneth Lonergan uses the snowy and frozen tints of winter in Massachusetts as a metaphor to illustrate the difficulty of the main character to deal with his feelings and difficult past (Lonergan, 2016). Sequences with dialogue are interwoven with purely atmospheric shots: for example, a flock of birds flying away is shown after a conversation where the protagonist is concerned about leaving.

Moreover, scholar Kathryn Millard evokes the evolution of technology and its impact on the methods of screenwriting, further describing the importance of images and sound in scripts (Millard, 2010). This notion reinforces the role of the senses in the perception of a story and its characteristics.

\section{Movement}

The concept of 'movement-image' is significant in redefining the role of images in storytelling: according to Gilles Deleuze, 'movement expresses a change in duration' (Deleuze 1986, p. 8). There is an abstract existence of movement within the image, which does not relate to video editing, but instead resides in the properties of the picture. It can be observed in silent movies, for instance in The Cameraman, when narratives had limited ways of communicating their message, but were based on sophisticated choreographies (Sedgwick, 1928). This idea of movement, according to Gilles Deleuze, is intrinsic to the image, and creates a passage of time as well as a motion in the brain of the audience. In fact, the notion implies the existence of an inner dimension of narrative that is already existent in the image, even if it does not externally display any motion. On that note, according to Henri Bergson, 'a passage is a movement and a halt is an immobility' (Bergson, Paul \& Palmer, 1991, p. 247). 
Cinematography does not necessarily need to use moving images, because they could interrupt the narrative on the level of interaction with the visuals. For example, director Chris Marker uses a slideshow technique to tell his science-fiction story in La Jetée; still images create an efficient and convincing narrative (Marker, 1962). Contemplation gives access to this dimension, by letting the viewer understand the 'story within the story' (Khatib 2012, p. 154). In this situation, a narrative is instilled with a parallel story, which expresses ideas within itself. Surprisingly, the abstract version of the story does not need a visual existence: it can emerge from the use of segments that are not part of the action, similar to b-rolls. It operates through the perception of space, in the images and the sensations cinematography can generate. But to allow this recognition, there needs to be sufficient time to process, decipher and interpret what is on screen.

The discussion about motion relocates more clearly the role of cinematography: it can be seen as 'the inscription of movement, a writing with movement' (Stewart, 2008, p. 29). In this regard, the image is given an internal dimension. But with movement, it is 'not an abstraction but an emancipation' (Moulard-Leonard, 2008, p. 107). This is crucial, because not only time lies within the image of a film, but also movement gives this very same image a development and an additional meaning, not in its characteristics, but here, in the freedom the image implies outside of its existence. The notion of movement and the impression it generates are an inherent quality of film pictures. This complex, but intrinsic nature of images suggests that suggested movement offers a new layer to understand the story. This layer could be replacing the narrative development in time, and generate meaning to the viewer in space. In reality, there are both an implied movement and a visible one that exist at the same time in a film.

The movements in Charlie Chaplin's silent film Modern Times exemplify these connections: they are an integral part of the narrative and its development, but no sound or dialogue can support this method-it is exclusively visual (Chaplin, 1936). The film was made at a time when other productions were focusing on dialogues, with the new medium of sound in film. Although Charlie Chaplin had the option to direct a talking motion picture, he decided to rely on intertitles and dynamic action.

Considering the essential features of cinematography, New York City-based experimental film \& uses the concept of motion existing in the images to replace the role of the narrative, but with intervals as the only components of the story (van Eenoo, 2017). Manhattan becomes the main character of the story, and through its unique aesthetic unfolds the narrative. The development of the new storytelling method based on pictures is implied and does not require the mechanism of cause-and-effect.

\section{Narrative Features}

Cinematography is often a key feature of a film's originality, as it has a strong impact on the viewer's ability to apprehend the overall tonality, mood and sense of discourse. Specific technical aspects of the medium can be considered: image color, grain, texture, and filters. Scholar Ian Garwood examines this particular aspect of cinematic storytelling: the focus is on the sensuous characteristics of cinematic images. The author analyzes films for the properties of their pictures to communicate certain impressions and for the manipulation of their visual features as narrative tools (Garwood, 2013, p. 3). In his study, Ian Garwood demonstrates how aesthetic values correlate with the narrative exercise. Using selected case studies from independent and mainstream cinema, he underlines the idea that the audience, by becoming aware of explicit emotions related to purely technical qualities, can connect to the story in an additional dimension to the script. The study identifies important characteristics of the images that support, embody or lead the narrative, and can, as such, be storytelling methodologies.

There is an emotional response to image grain that can be associated with realistic experience, to transpose the cinematic sensations closer to the feeling of a character, rather than the development of the story. Of course, perception depends on the various backgrounds, types of sensitivity and receptivity of the audience. But to be able to read the different strata of the film, it must operate on different levels, utilize more than a composition of scenes, and also the visual impact of images.

For example, in I'm Not There by Todd Haynes, an atypical narrative takes place: the central character, musician Bob Dylan, is impersonated by different actors, a woman, a young boy and four men (Haynes, 2007). A combination of six separate segments represents a part of the protagonist's personality. To support that method, the director uses different attributes for the images: monochrome and color scenes, textures, viewpoints and angles. The story also employs multiple narrators: every time there is a character, a new perspective on the musician is revealed. In some cases, the different stories intersect and the filming accompanies the situation with camera movements. Each persona being entirely distinct, it embodies a distinct visual style, offers a different perspective, and carries a different meaning. This strategy overcomes the composition of the plot itself: the narrative is not based on the structure of the story, but on the sensations that all the segments can communicate, individually and as a whole. In extension, the separate aspects are linked to each other in their linear interaction, opposed in their aesthetic, and compared in their meaning. From that point of view, it is an innovative process of filmmaking and of storytelling. 
In addition, depth of field, perspective and focal length are technical instruments of storytelling that allow the operation of the work on a purely visual level, with no relation to time or structure. The understanding of a scene can be approached by the visual different layers that appear on screen. By choosing to focus on a specific object or character, the out-of-focus areas can reveal key elements of the scene, and convey a very specific message, directly linked to the plot and its development.

However, art-cinema does not systematically require a clear sense of achievement for the story to operate. Film theorist David Bordwell describes the 'parametric narrative', based on the notions of fabula and syuzhet (Bordwell, 1985, p. 49). In this model, the audience understand the story of a film on the basis of three strategies: the 'prototype schemata' is to identify the protagonists, antagonists, the situation and the background; the 'template schemata' is the basic plot; the 'procedural schemata' allows the spectator to make sense of the succession of events with relations of causality (Bordwell, 1985, p. 36). But the author demonstrates that style can subdue the importance of the plot (Bordwell, 1985, p. 289). In this sense, cinematic storytelling is free to create its set of rules using plot construction, but also images - as well as sound and editing-as narrative instruments.

For example, in Inland Empire, director David Lynch uses surrealistic images, especially scenes with a giant rabbit in a mysterious television show, to build a dream-like narrative that visually leads the action, helping to connect the different pieces of the enigma (Lynch, 2006). But it is not the characters, nor their actions, that drive the plot. The implied atmosphere truly supports the development of the story, amid confusing location logics, obscure film sets, double personalities, and surrealistic characters. This technique is emerging as an effective tool to connect the abstract scenes of the movie, to make the narrative apprehensible, but also give the film its inventive visual style.

Another illustration of an unorthodox approach to filmmaking, Shadows (Cassavetes, 1959) was made with no written script (Viera, 1990, p. 34). This perspective signals a different approach to film narrative, where the story is not limited to a structure of scenes prepared in a causal relation, but can be dependent on other factors, such as actors and locations. It offers flexibility and allows for further exploration-in time as well as space. In fact, this is how the movie Shadows owns its realistic style; it resembles real life events with its rhythm and depiction of duration, free from the constraints of a written document. In addition, there is a dynamic dimension: philosopher Hubert Damisch compares Cassavetes' use of narrative process in cinema to the action paintings of artist Jackson Pollock (Mouëllic, 2014, pp. 71-98).

In a radical approach, Bagdad Cafe, by Percy Adlon, relies on the peculiar atmosphere of the film, transforming the experience of storytelling into an experience of sensations (Adlon, 1987).

Comparably, in an attempt to approach cinematic storytelling with a new angle, filmmaker Trần Anh Hùng, who directed The Scent of Green Papaya (Hùng, 1993), shared his refusal of traditional narrative techniques, striving to create a different language to tell his stories, and claiming his films can be better understood without reason, to challenge the spectator's feelings (Lim, 2017).

\section{Conclusion}

Images can appear intrinsically connected to the exercise of storytelling. Throughout this study, it appears clear that aesthetic values correlate with narrative methods; the audience, by becoming aware of explicit emotions related to technical visual qualities of the image, can relate to the story in an additional dimension to the script. The images of the movie, with their inherent qualities, support, embody the narrative delivery, guide the plot development and become fundamental storytelling instruments. Pictures can be approached as an essential narrative mechanism that can be intertwined with the writing and making of the story. Ultimately, cinematography is the 'film's form and style' (Bordwell, 2007, p. 129). And in an experimental approach to storytelling, both notions can serve the work as operating systems of the narrative. Ultimately, in this approach, the properties and qualities of movie images transform themselves into the messengers of the narrative that direct. In this perspective, images can become the primary instrument of storytelling, communicating emotion as the fundamental element of narrative, as opposed to a cause-and-effect configuration. The written story remains a guide that does not necessarily require cognitive reasoning. This calls for a more reflective and introspective approach to viewing film: a less passive and more engaging experience, where the audience is involved in the interpretation of the movie through contemplation and meaning-making.

\section{References}

Adlon, P. (Director). (1987). Bagdad Cafe [Motion Picture]. Germany: Filmverlag der Autoren.

Bergson, H., Paul, N. M., \& Palmer, W. S. (2004). Matter and Memory. Courier Corporation.

Bordwell, D. (2013). Narration in the Fiction Film. Routledge.

Bordwell, D. (1989). Historical Poetics of Cinema. The Cinematic Text: Methods and Approaches, 3, 369-398.

Bordwell, D. (1979). The Art Cinema as a Mode of Film Practice. Film Criticism, 4(1), 56-64.

Cobley, P. (2013). Narrative. Routledge. 
David, I. (2014). Screenwriting and Emotional Rhythm. Journal of Screenwriting, 5(1), 47-57.

Deleuze, G., Habberjam, B., \& Tomlinson, H. (1986). The movement-Image. Minneapolis: University of Minnesota.

Deleuze, G. (1989). Cinema II: The Time-Image. Bloomsbury Publishing.

De Sica, V. (Director). (1948). Bicycle Thieves. [Motion Picture]. Italy: Ente Nazionale Industrie Cinematografiche.

Cassavetes, J. (Director). (1959). Shadows. [Motion Picture]. United States of America: The Criterion Collection. Chaplin, C. (Director). (1936). Modern Times. [Motion Picture]. United States of America: United Artists.

Cinematography. (s.v.) In Merriam-Webster's Dictionary. Retrieved from URL: https://www.dictionary.com/browse/cinematography.

Degli-Esposti, C. (Ed.). (1998). Postmodernism in the Cinema. Berghahn Books.

Doane, M. A. (2003). The Close-Up: Scale and Detail in the Cinema. Differences: A Journal of Feminist Cultural Studies, 14(3), 89-111.

Elliot, A. J., \& Maier, M. A. (2007). Color and Psychological Functioning. Current directions in psychological science, 16(5),250-254.

Epstein, J., \& Liebman, S. (1977). Magnification and Other Writings. October, 9-25.

Ford, J. (Director). (1956). The Searcher. [Motion Picture]. United States of America: Warner Bros.

Garwood, I. (2015). Sense of Film Narration. Edinburgh University Press.

Goldstein, K. (1942). Some Experimental Observations Concerning the Influence of Colors on the Function of the Organism.Occupational Therapy.

Graham, T. S., Ackermann, J. C., \& Maxwell, K. K. (2004). Reel leadership II: Getting emotional at the Movies. Journal of Leadership Education, 3(3), 44-57.

Greenhalgh, C. (2005). How Cinematography Creates Meaning in Happy Together (Wong Kar-Wai, 1997). Style and Meaning: Studies in the Detailed Analysis of Film, 195-213.

Geuens, J. P. (2002). The Digital World Picture. Film Quart, 55(4), 16-27.

Haynes, T. (Director). (2007). I'm Not There. [Motion Picture]. United States of America: The Weinstein Company.

Hùng T. A. (Director). (1993). The Scent of Green Papaya. [Motion Picture]. United States of America: GoDigital Media Group.

Juniper, A. (2011). Wabi Sabi: The Japanese Art of impermanence. Tuttle Publishing.

Khatib, L. (2013). Storytelling in World Cinemas: Contexts (Vol. 2). Columbia University Press.

Kohn, E. (2012, February 9). An Interview with Béla Tarr: Why He Says 'The Turin horse' is His Final Film. Indie Wire. Retrieved from URL: http://www.indiewire.com/article/bela-tarr-explains-why-the-turin-horseis-his-final-film.

Koehler, R. (2011). The Thinking Image: Fred Kelemen on Béla Tarr and The Turin Horse. Cinema Scope, 46.

Lankow, J., Ritchie, J., \& Crooks, R. (2012). Infographics: The power of Visual Storytelling. John Wiley \& Sons.

Lim, G. (2016, November 26) Trần Anh Hùng Masterclass Transcribed. 30th Singapore International Film Festival. Retrieved from URL: https://sgiff.com/trananhhung-masterclass-transcribed.

Lynch, D. (Director). (2006). Inland Empire. [Motion Picture]. United States of America: 518 Media.

Carter, P. (2014). James Boswell's Manliness. In English Masculinities, 1660-1800 (pp. 121-140). Routledge.

Manovich, L. (1996). Cinema and Digital Media. Perspectives of Media Art. Ostfildern, Germany: Cantz Verlag.

Marker, C. (Director). (1962). La Jetée. [Motion Picture]. France: Argos Films.

Meirelles, F. \& and Lund, K. (Directors). (2002). City of God. [Motion Picture]. United States of America: Miramax.

Moulard-Leonard, V. (2008). Bergson-Deleuze Encounters: Transcendental Experience and the Thought of the Virtual. SUNY Press.

Nichols, J. (Director). (2011). Take Shelter. [Motion Picture]. United States of America: Sony Pictures Classics.

Rognoli, V., \& Karana, E. (2014). Toward a New Materials Aesthetic Based on Imperfection and Graceful Aging. In Materials Experience (pp. 145-154). Butterworth-Heinemann.

Plantinga, C. (2009). Moving Viewers: American Film and the Spectator's Experience. University of California Press.

Prince, G. (2012). A Grammar of Stories: An Introduction (Vol. 13). Walter de Gruyter.

Prince, S. (2004). The Emergence of Filmic Artifacts: Cinema and Cinematography in the Digital Era. Fim Quart, 57(3), 24-33.

Sayre, H. M. (1983). The Object of Performance: Aesthetics in the Seventies. The Georgia Review, 37(1), 169188.

Sedgwick, E. (Director). (1928). The Cameraman. [Motion Picture]. United States of America: Metro-GoldwynMayer.

Stewart, G. (2008). Framed time: Toward a Postfilmic Cinema. University of Chicago Press. 
Tarkovsky, A., \& Hunter-Blair, K. (1989). Sculpting in Time: Reflections on the Cinema. University of Texas Press.

Tarr, B. \& Hranitzky, Á. (Directors). (2011). The Turin Horse. [Motion Picture]. Hungary: Cirko Film.

Tati, J. (Director). (1967). Playtime. [Motion Picture]. France: Specta Films.

van Eenoo, C. (Director). (2017). \&. [Motion Picture]. United States of America: 309093.

van Gogh, V. (1885). The Potato Eaters (Oil on Canvas). Amsterdam: Van Gogh Museum.

Verstraten, P. (2009). Film Narratology. University of Toronto Press.

Wartenberg, T. (2004, August 18). Philosophy of Film. The Stanford Encyclopedia of Philosophy. Retrieved from URL: https://plato.stanford.edu/archives/win2015/entries/film.

Wong, K.W. (Director). (1997). Happy Together. [Motion Picture]. Hong Kong: Golden Harvest Company.

Zophoníasson. B. (Director). (2014). Life in a Fishbowl. [Motion Picture]. Iceland: Icelandic Film Company. 